\title{
Antibiotika-Resistenzen: Die Politik redet, Ärzte handeln
}

\begin{abstract}
Die Politik hat sich 2015 erstmals groß dem Thema Antibiotika-Resistenzen gewidmet. Aber hatte das auch Auswirkungen auf den Praxisalltag? Und wie gehen einzelne Fachgruppen das Problem an? Springer Medizin hat vier Kollegen aus vier Disziplinen gefragt.
\end{abstract}

Springer Medizin: Die große Politik hat sich in den vergangenen Monaten intensiv mit dem Thema „Antibiotika-Resistenz" befasst. Gröhes 10-Punkte-Plan, DART 2020, G7-Gipfel - was ist davon in Ihrer Praxis angekommen? Kardos: Wir haben schon viel früher gewusst, dass Antibiotika-Resistenzen ein bedrohliches Problem darstellen. Das Problem hat ja verschiedene Seiten, z. B. die Entwicklung der Antibiotika durch die Pharmaindustrie, was ja nicht das günstigste Geschäft ist. Andererseits die maßlose Anwendung. Es ist bekannt, dass je häufiger sie ein Antibiotikum einsetzen, umso höher wird die Resistenzrate sein.

Die Politik redet, Ärzte müssen handeln - wie gehen Sie bei der Therapie von Atemwegsinfekten vor, um der Entstehung von Antibiotika-Resistenzen entgegenzuwirken?

Kardos: Es ist gut bekannt, dass 60-70\% der gesamten humanmedizinischen Antibiotika-Verordnungen auf die Atemwege - obere und untere - und auf die Harnwege entfallen. Und deshalb, sind das die zwei wichtigsten Zielgruppen, die unter den Ärzten angesprochen werden müssen. Im Bereich der Atemwege sind die weitaus meisten Infekte ja viraler Natur, da wirken Antibiotika ohnehin nicht. Für den einzelnen ist das gar nicht erfassbar, wenn es ihm nach drei bis fünf Tagen besser geht, ob das eine direkte Folge der Antibiotika-Therapie war oder ob es ihm ansonsten genauso gut ergangen wäre.

Welchen Stellenwert haben Phytopharmaka in Ihrer Praxis bei der Behandlung von Atemwegsinfekten?

Kardos: Akute Atemwegsinfekte benötigen eine Behandlung, die Patienten leiden, aber andererseits klingen akute Atemwegsinfekte auch spontan ab, selbst wenn es 10 bis 12 Tage dauert. Heute ist die häufigste Behandlung ein Antibiotikum, obwohl allgemein bekannt, dass es sich um eine virale Infektion handelt. Wenn wir hier wirksame Präparate haben, die ihre Wirksamkeit gegenüber Placebo in randomisierten, kontrollierten Studien nachgewiesen haben,

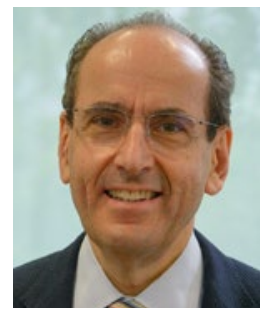

Dr. med. Peter Kardos

ist Facharzt für Innere Medizin, er arbeitet in einer Gemeinschaftspraxis für Allergologie, Pneumologie und Schlafmedizin in Frankfurt am Main

dann haben wir gewonnen: Dem Patienten wird geholfen, Antibiotika-Resistenzen werden nicht gezüchtet. Es gibt Phytopharmaka, die ihre Wirksamkeit in kontrollierten, randomisierten Studien nachgewiesen haben.

Wenn Sie Ihre eigene Fachgruppe betrachten, im Hinblick auf deren Rolle beim Trend hin zum rationalen Einsatz von Antibiotika, wo sehen Sie die Pneumologen: Vorreiter oder Schlusslicht?

Kardos: Wir Pneumologen halten uns immer für Vorreiter, aber da ist auch sicherlich noch etliches zu tun. Erkältungskrankheiten werden in der Regel beim Hausarzt behandelt. Zu uns kommen Patienten mit Exazerbationen, also akuten infektbedingten Verschlechterungen etwa einer COPD. Diese sind häufig viral verursacht, werden aber mit Antibiotika behandelt. Es ist sicherlich so, dass in mindestens $50 \%$, wenn nicht sogar $70 \%$ der Fälle, die antibiotische Behandlung für die Exazerbation der COPD eingespart werden könnte. Das ginge nur unter entsprechender Kontrolle des Patienten, man muss wieder einbestellen. Patienten und Gesellschaft profitieren, wenn man Antibiotika nur dann verordnet, wenn es unbedingt sein muss.

Das Interview führte Andrea Wehrens.

\section{Interviews im Video}

Unter http://tinyurl.com/zcmz6kj können Sie das Interview mit Dr. med. Peter Kardos und seinen Kollegen aus der Kinder- und Jugendmedizin, der Allgemeinmedizin und der HNO-Heilkunde als Video sehen.

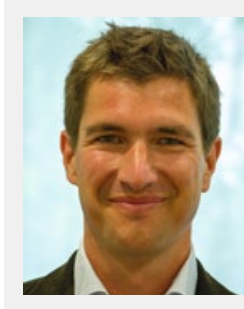

Dr. Daniel Seng, Facharzt für Kinder und Jugendmedizin, Unterschleißheim bei München

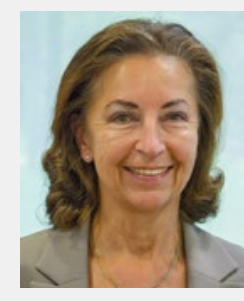

Dr. Margit Hollenz, Fachärztin für Allgemeinmedizin, Rödental

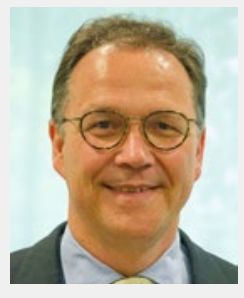

Prof. Dr. Ludger Klimek ist Facharzt für HNOHeilkunde am Zentrum für Rhinologie und Allergologie in Wiesbaden 